\title{
PRAEFATIO EDITORIS
}

Postquam ea quae scriptores antiqui tradiderunt cum memoria earum rerum de quibus monumenta certissime testantur coniungi atque componi coepta sunt, cum totius fere antiquitatis historia saeculo nostro correcta aucta amplificata sit, tum aetas Romanorum imperatoria ex ingenti monumentorum copia quasi nova quadam luce illustrata est. Atque etian hominum qui illa aetate vel in rebus publicis vel in litteris clari fuerunt memoriam cum scripta quae aetatem tulerunt mancam reliquissent vel iniuria temporum prorsus oblivione obruisset, adhibitis titulorum nummorumque testimoniis redintegrari posse virorum doctorum temptamina quaedam veluti indices ad Plinii epistulas a Mommseno, ad Acta Arvalium ab Henzeno confecti omnibus ante oculos posuerant. Qui indices quamquam artis finibus circumseripti erant, cum opera eiusmodi permultum ad aetatis imperatoriae meliorem eognitionem conferre posse luculenter demonstrassent, Academia Regia Borussica decrevit ut totius aetatis principatus inde ab Augusto usque ad Diocletianum Prosopographia conderetur, eo consilio ut quaecunque de hominibus illius aetatis notabilibus vel per scriptores vel per titulos nummosque memoriae tradita sunt colligerentur et componerentur. Cuius operis curam Academia munere tripartito Elimaro Klebs, Hermanno Dessau, Paulo von Rohden mandavit. Atque volumen primum Klebs, alterum Dessau confecit; tertium ne simul cum his quae nune in publicum prodeunt ederetur, gravis Pauli von Rohden valetudo obstitit. Vnde tertii voluminis ad finem perducendi curam Dessau in se suscepit. Quo confecto quartum addere in animo est, quod fastos consulares et latereulos eorum qui honoribus et muneribus publicis functi sunt continebit. 


\section{- VIII -}

Ex legibus autem quibus ut editores in opere tractando tenerentur Academia decrevit, haec fere ad syllogen recte adbibendam digna videntur quae paucis hoc loco repetantur:

Terminos operis Academia constituit annum pugnae Actiacae et initium imperii Diocletiani. Sed etiam eorum quorum aetas utrum paullo superior an inferior fuerit non certe diiudicare licet nonnunquam ratio habita est.

Romanorum recepti sunt homines ordinis senatorii quicunque innotuerunt, ordinis equestris ii qui imperatorum negotia gesserunt, item eorum cognati familiaresque. Neque minus Romanorum quorum praeterea apud scriptores mentio fit plerique memorati sunt, inprimis ii quorum nomina apud rerum scriptores inveniuntur. Sed hominum plebeiorum infinita illa turba qua scripta ecclesiastica et auctorum iuris referta sunt procul semota est. Haec de Romanis. Graecorum autem et barbarorum hominum selecti tantum recepti sunt et ii quidem qui cum Romanis vel rebus vel hominibus quodam modo coniuncti fuerunt.

Quae ex scriptoribus titulis nummis de iis quorum nomina recepta sunt adhuc innotuerunt, ea plene, quantum in materia maxime dispersa fieri potuit, allata sunt. Sed et in imperatoribus Romanis omissis rebus quas imperium adepti gesserunt ea quae ad vitam privatorum spectant memorata sunt et de regibus barbarorum quae scitu maxime digna erant afferre satis visum est. Denique de scriptis eorum qui litterarum laude floruerunt pluribus agere non fuit consilium, quoniam qui litterarum historias condiderunt satis copiose de iis disputaverunt.

Romanorum hominum nomina per litterarum ordinem ex gentiliciis, quatenus innotuerunt vel probabiliter restitui potuerunt, sunt disposita. De Graecis autem et barbaris iis qui civitate Romana ornati tria nomina gesserunt plerumque sub cognominibus actum est. Homines polyonymi vel sub primo nomine vel sub eo quod fuit principale ac re vera paternum tractati sunt. Quicunque pluribus nominibus more Romano formatis usi sunt, eorum nomina nuda sub uno quoque nomine repetita sunt. Veluti de C. Antio Iulio Quadrato sub Iulio disputatum est, nomina repetita sunt sub Antio et sub Quadrato.

De forma denique operis monendum est litteris quadratis nomina hominum ordinis senatorii impressa esse, titulos qui Corpore Inscriptionum Latinarum continentur plerumque per numeros nudos indicari. 'Fasti' ad quos lectores saepe ubi de consulatuum indicationibus agitur relegantur, sunt fasti consulares quos volumen quartum exhibebit. 
In eodem volumine etiam 'Additamenta' totius operis edentur. Nam cum opus per quinquennium prelo subiciatur, fieri non potest quin ex seriptis virorum doctorum quae interim prodierunt vel ex titulis recens repertis vel rectius quam antea lectis alia addenda, alia corrigenda sint neque iam in foliis impressis mutari potuerint. Itaque quae his de causis ut mutentur restat et si quae alias ab editoribus omissa vel minus recte exposita sunt, ea in Additamentis corrigere atque supplere consilium est.

Ser. Berolini mense

Decembri a. 1896.

E. KLEBS. 
